\title{
Abrasion Resistance, Flexural Toughness and Impact Resistance of Rubberized Concrete
}

\author{
Hatem H. Ibrahim, Ahmed Z. Saber, Hossam A. Hodhod
}

\begin{abstract}
This study aimed to investigate abrasion resistance, flexural toughness and impact resistance of concrete mixes with incorporated particles of crumb rubber (CR) as a partial substituent by volume to concrete natural aggregates. Seven concrete mixes were prepared with water to cement ratio 0.4 and cement content $450 \mathrm{~kg} / \mathrm{m}^{3}$. One mix, with no rubber content, was considered as a reference mix to compare the designated mechanical properties of plain rubberized mixes, while the remaining six mixes contained crumb rubber as a partial replacer at levels of $10 \%, 20 \%$ and $30 \%$ by volume of each sand and crushed stone aggregates. Abrasion resistance was evaluated according to British standard BS 1338 and impact resistance was measured according to ACI 544.2R. It has been discovered that increasing $C R$ replacement level led to a significant improvement in abrasion resistance, flexural toughness, and impact resistance (number of blows that cause failure cracking). Abrasion lengths decreased by 3.0 - 20.6\%, while flexural toughness and impact resistance increased by 8.2 - 39.4\% and 18.7 - 365.4\% respectively with increasing crumb rubber replacement level.
\end{abstract}

Keywords: Crumb rubber; rubberized concrete; abrasion resistance; impact resistance; flexural toughness.

\section{INTRODUCTION}

The disposal of waste tires is a significant environmental problem around the world. Billions of waste tires are annually manufactured around the world ${ }^{(28 ; 30)}$. Millions of scrap rubber of these tires are annually thrown away, discarded or buried into soil, causing dangerous issue to the surrounding ecological system. It had been estimated that, by the end of every year, about 500 millions of tires would be regularly discarded to garbage or landfills without any kind of treatment. Moreover, this number is predicted to reach 1200 million annually by the end of year 2030. Considering stockpiled tires, 5000 million of scraped tires are regularly discarded ${ }^{(5 ; 11 ; 29)}$. Tires are eliminated by many ways, such as, land filling, or, burning to be used as fuel or to produce black carbon. Stockpiled

Revised Manuscript Received on February 05, 2020.

* Correspondence Author

Hatem H. Ibrahim, Corresponding author, Assistant Professor, Structural Engineering Department, Faculty of Engineering, Cairo University, Giza, Egypt. Email: hibrahim@eng.cu.edu.eg

Ahmed Z. Saber, Master Student, Structural Engineering Department, Faculty of Engineering, Cairo University, Giza, Egypt. E-mail: ahmedza.saber@gmail.com

Hossam A. Hodhod, Professor, Structural Engineering Department, Faculty of Engineering, Cairo University, Giza, Egypt. Email: hodhodh2002@yahoo.com

(c) The Authors. Published by Blue Eyes Intelligence Engineering and Sciences Publication (BEIESP). This is an open access article under the CC BY-NC-ND license (http://creativecommons.org/licenses/by-nc-nd/4.0/) tires have significant impact on health and environment through water, air and soils pollution. These tires keep the water for long period due to its impermeable nature that provides breeding for pests and mosquitoes ${ }^{(12 ; 6 ; 20)}$. Burning of scraped tires is the cheapest and easiest way for disposal, which causes fire hazards. Atmosphere temperature in this area increases and the produced smoke is saturated with very harmful constituents that harm humans, plants and animals. Bitumen and Styrene are produced from petrochemical industry and are the main component in manufacturing tires. Burning of tires emits several amounts of benzene and styrene. Butadiene is four-carbon element which is released during combustion of polymer butadiene and styrene. Pollutants produced from burning black smoke, impairs visibility. Toxic gases emissions are including hydro carbons, $\mathrm{CO}, \mathrm{NO}_{2}$ and $\mathrm{SO}_{2}$.

After burning, left powder pollutes soils ${ }^{(6 ; 20 ; 31)}$. Using waste tires as fuels in not economically attractive. Produced black carbon from combustion process is expensive and has less quality if compared to black carbon produced from manufactured petroleum products. Waste rubber of scraped tires could be utilized in many applications. Such applications as road construction, soil sealage in agriculture, onshore breakwaters, estuaries to absorb ships impact, retaining walls at harbors, fishing facilitation at artificial reefs, fuel for cement furnace and incineration to produce electricity ${ }^{(27 ; 24 ; 7 ; 20)}$. Other example of utilizing rubber in construction is the production of geopolymer interlocking bricks that enhanced by crumb rubber ${ }^{(20)}$. But still, many millions of scraped tires are thrown away, burnt and buried around the world.

In the last years, construction industry was working on sustainability in production by finding more environment friendly materials or by using waste materials in concrete. Incorporating waste tires rubber into concrete as a partial replacement to its natural aggregates is a better solution to deal with scraped tires. This solution is friendly to environment, since it diminishes emission of carbon dioxide by preventing combustion of tires ${ }^{(26 ; 18 ; 5 ; 23)}$. Other researchers got deeper into this by creating FE model to simulate the effect of using waste materials as aggregates in concrete and they updated the model by experimental results $^{(19)}$.

Gesoğlu et al. ${ }^{(15)}$ investigated the effect of replacing part of the coarse aggregate in pervious concrete by waste rubbers. They used tire rubber with 10 and $20 \%$ of coarse aggregate volume with reducing coarse aggregate with the same percent. 


\section{Abrasion Resistance, Flexural Toughness and Impact Resistance of Rubberized Concrete}

They indicated that rubberized concrete abrasion resistance is improved with incorporating rubber particles into concrete up to $20 \%$ as replacement to natural aggregates. They also mentioned that crumb rubber fine particles showed improved abrasion resistance compared to crumb rubber coarse particles.

Previous findings were confirmed by Ismail and Hassan ${ }^{(17)}$. They performed bending test on large-scaled beams whose concrete is enhanced with different percentages of rubber. It was reported that flexural toughness and deformability of all tested beams with incorporated particles of crumb rubber were increased at the same comparable value, which indicated more energy absorption. However, more increase in rubber content led to reduction in flexural toughness when compared to control mix. Flexural toughness reduced by $9 \%$ and $21.8 \%$ for $15 \%$ and $25 \%$ rubber content, respectively.

Gerges et al. ${ }^{(13)}$ used rubber powder as partial replacement of the fine aggregate in concrete. According to impact load test using the impact drop load, the optimal replacement percentage is $5 \%$ of fine aggregate because it gave the maximum number of drops.

Gupta et al. ${ }^{(16)}$ prepared cylindrical concrete specimens (150 mm diameter x $65 \mathrm{~mm}$ height) with incorporated rubber fibers and tested these specimens in impact in the same manner presented herein in this research. It was observed that increasing replacement percent of rubber fibers led to increasing impact resistance and increasing difference in numbers of blows causing initial and ultimate crack.

In this study, crumb rubber was utilized into concrete as a partial substituent by volume for each fine and coarse concrete natural aggregates at replacement levels $10 \%$, $20 \%$ and $30 \%$. Control concrete mix was prepared six other mixes containing crumb rubber at previously mentioned replacement levels. All concrete mixes were prepared with w/c 0.4 and cement content $450 \mathrm{~kg} / \mathrm{m}^{3}$, in addition to high range water reducer at $1 \%$ by weight of cement to improve viscosity of concrete mixture. Mechanical properties of concrete such as abrasion resistance, flexural toughness and impact resistance have been studied.

\section{RESEARCH SIGNIFICANCE}

Many applications require improved specific mechanical properties of concrete. Such applications involve concrete subjected to exposures, such as sliding, skidding, rubbing of objects on concrete surface or even foot and tire pressure directly to surface. The rough surface is, the more resistance is achieved to such exposures, meaning lower abrasion. While, for structural elements subjected to cyclic loading such as wind loads, seismic loads and any vibration load, these elements would preferably have improved flexural toughness. On the other hand, elements subjected to sudden impact loads such as vehicular collision barriers, structural blast elements and industrial floors shall behave higher impact resistance. Incorporating particles of crumb rubber into concrete mixtures as a partial replacement to concrete natural aggregates, improves the fore mentioned desired mechanical properties in addition to clean disposal of waste tire materials which is considered a green and friendly solution to surrounding environment.

\section{EXPERIMENTAL PROGRAM}

\subsection{Materials}

Type CEM I, 42.5 N Egyptian Portland cement according to BS EN 197-1/2011 was used as the cementitious material. Natural sand and $19 \mathrm{~mm}$ crushed dolomite stone aggregate were used as natural fine and coarse aggregates, respectively. Both aggregates with a specific gravity of 2.52 and absorption of $1.1 \%$. A crumb rubber aggregate with a specific gravity of 1.03 and negligible absorption was used as a partial substituent of both fine and coarse aggregates in PRC mixtures. The aggregates' gradations of the $19 \mathrm{~mm}$ crushed dolomite stone, natural sand, and CR are presented in Figure 1. Chemical addicrete BVF high-range water-reducer admixture (HRWRA), having similar specifications to (14) was used to by $1 \%$ of cement weight in all concrete mixtures.

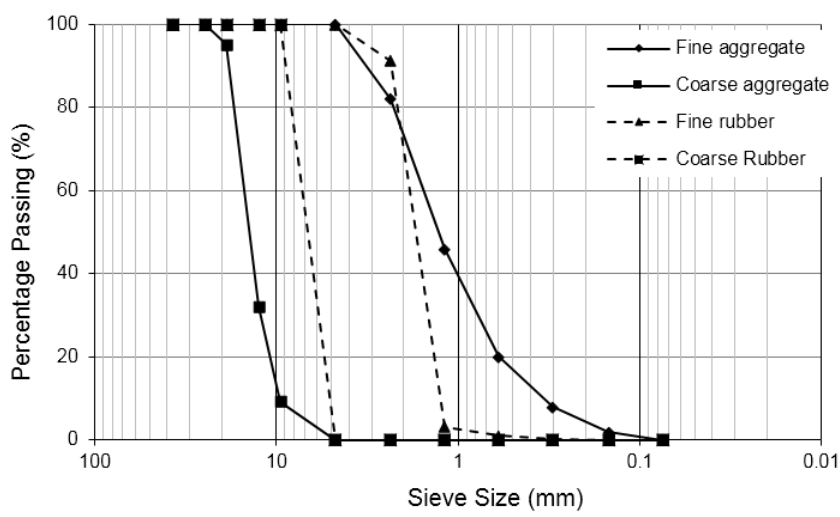

Figure 1. Grading Curves for Fine and Coarse Aggregate and Crumb Rubber.

\subsection{Concrete Mixtures}

In this study, concrete mixtures were selected based on a preliminary trial mixing stage. In this early stage, minimum water to cement ratio (w/c), maximum cement content and ratio of coarse aggregate to fine aggregate were obtained based on achieving acceptable visual flowability, no aggregates' segregation and minimum amount of chemical HRWRA. The results obtained were a water to cement ratio (w/c) of 0.4 , cement content of $450 \mathrm{~kg} / \mathrm{m}^{3}$ and coarse to fine aggregate ratio of 0.67 . The concrete mixtures utilized in the study were seven mixtures. One mixture was the control one, with no rubber replacement for the natural aggregates. The control mixture is designated to compare its obtained mechanical properties to other mixtures. Three mixtures were prepared with fine crumb rubber as a partial substituent to fine aggregate at replacement levels $10 \%, 20 \%$ and $30 \%$ by volume. While, additional three mixtures were also prepared with incorporated coarse crumb rubber as a partial replacer to coarse aggregates by volume at the same replacement levels $10 \%, 20 \%$ and $30 \%$.

\subsection{Fresh and Hardened Concrete Properties' tests}

Slump test was conducted on fresh concrete to measure its consistency and workability. The test was conducted according to ASTM C143/C143M-12. Concrete specimens before testing, were de-molded and exposed to curing in water according to ASTM C192/C192M-07. 
Compression test was conducted according to British standards BS EN 12390-3 using 150mm cubes. Abrasion resistance was conducted according to British standards BS 1338: 2003 using specimens $150 \mathrm{~mm} \times 150 \mathrm{~mm} \times 80 \mathrm{~mm}$ thickness. While, flexural toughness was conducted on concrete prisms $100 \mathrm{~mm} \times 100 \mathrm{~mm} \times 700 \mathrm{~mm}$ with LVDT at middle of the beam to measure the vertical deflection. Impact resistance was conducted according to ACI 544.2R using specimens $150 \mathrm{~mm} \times 150 \mathrm{~mm} \times 65 \mathrm{~mm}$ thickness. Results obtained for fresh properties of all tested concrete mixtures are presented in Table 1.

Table 1. Slump results of all concrete mixtures

\begin{tabular}{|l|c|c|}
\hline Mix & Rubber (\%) & Slump (mm) \\
\hline Control & 0 & 140 \\
\hline F-10 & 10 & 134 \\
\hline F-20 & 20 & 88 \\
\hline F-30 & 30 & 59 \\
\hline C-10 & 10 & 109 \\
\hline C-20 & 20 & 60 \\
\hline C-30 & 30 & 35 \\
\hline
\end{tabular}

\subsection{Compressive Test Setup}

Three concrete specimens for compressive strength test were prepared for 7 and 28 days compression test. Test was performed according to BS EN 12390-3 standard. Three cubes $150 \mathrm{~mm} \times 150 \mathrm{~mm} \times 150 \mathrm{~mm}$ were cast for each mix designated of the two testing dates. Tinius-Olsen UTM was used for testing all specimens. All cubes were de-molded after 24 hours and cured in water according to ASTM C192/C192M-02 standard till testing date.

\subsection{Abrasion Test Setup}

Three concrete specimens for each mixture were prepared and fixed to the abrasion device, which is manufactured and calibrated according to BS 1338: 2003 (Fig. 2). The abrasive material, fused alumina, with grit size of F80 filled the upper storage hopper. The electric motor was connected to worm gear box to reduce its speed to 75 revolution per minute. The counter weight was calibrated and connected to the trolley in ready to apply normal forces to testing specimens. Abrasion length of specimens is measured by Vernier caliper to nearest $0.01 \mathrm{~mm}$.

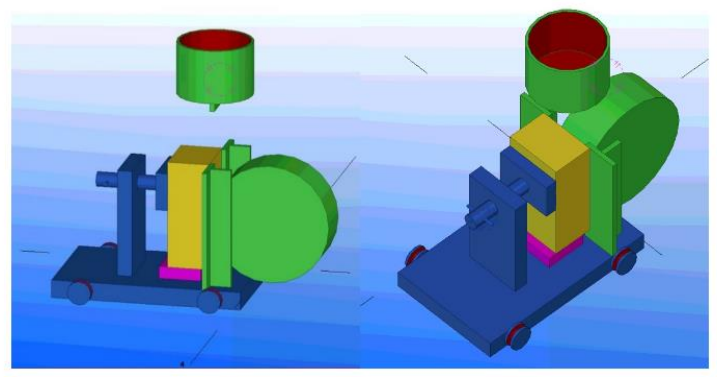

Figure 2. 3d Built-up TEKLA Model for The Abrasion Device in Preparation to Construction Phase.

\subsection{6.Flexural Toughness Test Setup}

Three-point loading flexural test was conducted on concrete prisms by using electrical hydraulic UTM SHIMADZU testing machine. Three concrete prisms, for each mixture, were tested in bending at 28 days. Before testing, loading surface was leveled with a high strength gypsum in order to eliminate eccentricity due to loading. Specimens were loaded by constant loading rate of 4 KN/min. Prisms were simply supported with loading span $600 \mathrm{~mm}$ length and free edge distance of $50 \mathrm{~mm}$. A linear variable displacement transducer (LVDT) was set below the middle of prism, point of loading, and connected to computer system to measure the actual deflection due to acting load. Load deflection curve is plotted and divided into $\mathrm{n}$ segments. Flexural toughness is calculated by summation of all absorbed energies for the segments under P- $\Delta$ curve, as the following formula is showing:

$E_{f t}=\sum_{i=1}^{n} E_{f t i}=\sum_{i=1}^{n} \frac{1}{2} *\left(P_{i}+P_{i-1}\right) *\left(\Delta_{i}-\Delta_{i-1}\right) ;$

Where:

$E_{f t}$ : Concrete flexural toughness, kN.mm

$E_{f t i}$ : Concrete flexural toughness at each load increment,

kN.mm

$P_{i}, P_{i-1}$ : Successive applied loads on concrete beam specimen, $\mathrm{kN}$

$\Delta_{i}, \Delta_{i-1}$ : Successive corresponding vertical beam deflections due to $\mathrm{P}_{\mathrm{i}}$ and $\mathrm{P}_{\mathrm{i}-1}$

\subsection{Impact Test Setup}

Concrete specimens were cast with overall dimensions of $150 \mathrm{~mm}$ squared cross section and $65 \mathrm{~mm}$ height. Three concrete specimens, for each mixture, were tested for impact at 28th days. All specimens were subjected to a drop down weight of $43.63 \mathrm{~N}$ of a spherical steel ball with $63.5 \mathrm{~mm}$ in diameter from a height of $457 \mathrm{~mm}$. Number of hammer blows which caused first obvious crack (N1) and specimen failure (N2) were recorded and corresponding absorbed energy was determined. Cracking pattern was observed for all concrete specimens representing all mixtures. Impact energy at any number of blows is calculated by the following formula:

$$
U_{i m}=n_{i m} W_{i m} H_{i m} ; \ldots \ldots \ldots \ldots \ldots \ldots \ldots \ldots \ldots \ldots \text { Eq (2) }
$$

Where:

$\mathrm{U}_{\mathrm{im}}$ : Impact energy absorbed by concrete specimen at $\mathrm{n}_{\mathrm{im}}$ blows, kN.mm

$\mathrm{n}_{\text {im }}$ : Number of blows of impacted specimens

$\mathrm{W}_{\mathrm{im}}$ : Weight of dropped hammer at impact, $\mathrm{kN}$

\section{$\mathrm{H}_{\mathrm{IM}}$ : DROP DOWN HEIGHT AT IMPACT, MM}

\section{EXPERIMENTAL RESULTS AND DISCUSSION}

\subsection{Compressive strength results discussion}

The results obtained from compression test for all concrete mixes are presented in Table 2. The results show that compressive strength of the control mix, with no contained crumb rubber, was $44.13 \mathrm{MPa}$ at the age of 28 days of concrete. Figure 3 shows the fracture pattern of control mix cube after the test. For rubberized concrete mixes with fine crumb rubber as a partial replacer to fine aggregates, it was found that compressive strengths, decreased to $37.75 \mathrm{MPa}$, 35.17 $\mathrm{MPa}$ and 31.53 MPa at replacement levels 10\%, 20\% and $30 \%$ respectively. Those values decreased by $14.4 \%$, $20.2 \%$ and $28.6 \%$ at the same previous replacement levels respectively, when compared to control mix.

Published By:

Blue Eyes Intelligence Engineering

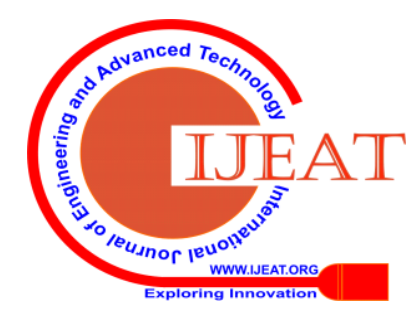


While, for other rubberized concrete mixes with coarse crumb rubber incorporated as a partial replacer to natural coarse aggregates, the results obtained from the test showed that compressive strengths diminished to $28.43 \mathrm{MPa}, 18.48$ $\mathrm{MPa}$ and $14.51 \mathrm{MPa}$ at rubber replacement levels 10\%, 20\% and $30 \%$ respectively. The results dropped by $35.6 \%, 58.1 \%$ and $67.1 \%$ relative to the control mix at the previous replacement levels respectively.

Table 2. Average compressive strength calculated for all concrete mixtures

\begin{tabular}{|l|c|c|}
\hline Mix & $\begin{array}{c}\text { Av Compressive strength } \\
\text { at 7 days }(\mathrm{MPa})\end{array}$ & $\begin{array}{c}\text { Av Compressive strength } \\
\text { at 28 days }(\mathrm{MPa})\end{array}$ \\
\hline Control & 41.31 & 44.13 \\
\hline F-10 & 37.01 & 37.75 \\
\hline F-20 & 34.58 & 35.17 \\
\hline F-30 & 30.91 & 31.53 \\
\hline C-10 & 21.85 & 28.43 \\
\hline C-20 & 17.37 & 18.48 \\
\hline C-30 & 13.23 & 14.51 \\
\hline
\end{tabular}

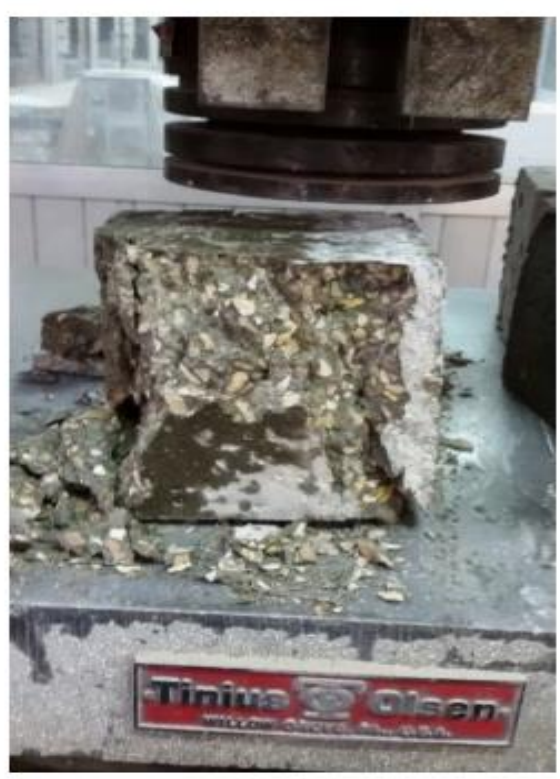

Figure 3. Control Specimen after Compression test.

\subsection{Abrasion resistance results discussion}

The results obtained from abrasion test for all concrete mixes are presented in Table 3. The results show that abrasion length of the control mix (Fig. 4), with no contained crumb rubber, was $34.56 \mathrm{~mm}$ at the age of 28 days of concrete. For rubberized concrete mixes with fine crumb rubber as a partial replacer to fine aggregates, it was found that abrasion lengths, as shown in Fig. 5, decreased to $32.53 \mathrm{~mm}, 29.48 \mathrm{~mm}$ and $27.44 \mathrm{~mm}$ at replacement levels $10 \%, 20 \%$ and $30 \%$ respectively. Those values decreased by $14.4 \%, 20.2 \%$ and $28.6 \%$ at the same previous replacement levels respectively, when compared to control mix.

Table 3. Abrasion lengths obtained for all concrete mixtures

\begin{tabular}{|l|c|c|c|c|}
\hline Mix & \multicolumn{3}{|c|}{ Abrasion length (mm) } & Av Abrasion length (mm) \\
\hline Control & 35.25 & 34.56 & 32.83 & 34.56 \\
\hline F-10 & 31.23 & 32.53 & 33.5 & 32.53 \\
\hline F-20 & 29.04 & 29.48 & 29.33 & 29.48 \\
\hline F-30 & 27.17 & 27.44 & 26.62 & 27.44 \\
\hline C-10 & 35.22 & 33.54 & 32.87 & 33.54 \\
\hline C-20 & 31.67 & 31.51 & 31.98 & 31.51 \\
\hline C-30 & 29.88 & 28.46 & 27.32 & 28.46 \\
\hline
\end{tabular}
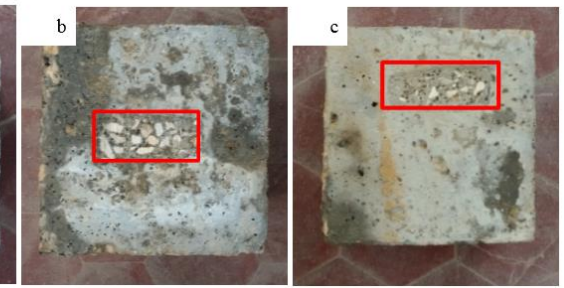

Figure 5. Abrasion test (a) F-10, (b) F-20, (c) F-30.

While, for other rubberized concrete mixes with coarse crumb rubber incorporated as a partial replacer to natural coarse aggregates, the results obtained from the test showed that abrasion lengths (Fig. 6) diminished to $33.54 \mathrm{~mm}, 31.51$ $\mathrm{mm}$ and $28.46 \mathrm{~mm}$ at rubber replacement levels 10\%, 20\% and $30 \%$ respectively. The results dropped by $3.0 \%, 8.8 \%$ and $17 \%$ relative to the control $\operatorname{mix}$ at the previous replacement levels respectively. Figure 7 shows the abrasion lengths measured after test for all concrete mixtures versus fine and coarse crumb rubber percentage.
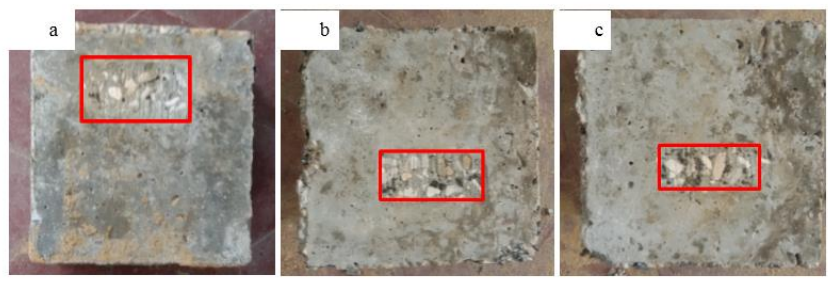

Figure 6. Abrasion test (a) C-10, (b) C-20, (c) C-30.

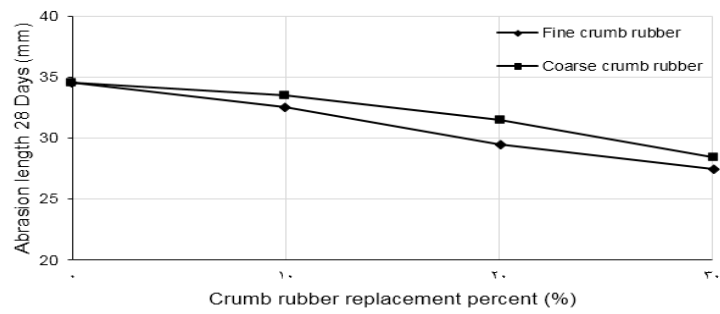

Figure 7. Abrasion lengths versus percent replacement by fine and coarse crumb rubber.

At the same replacement levels of crumb rubber to natural aggregates, it was found that reduction in abrasion length of mixes with fine crumb rubber is larger than that reduction in abrasion length of mixes with coarse crumb rubber. Abrasion length slightly decreased at 10 percent replacement by crumb rubber when compared to the higher replacement levels at $20 \%$ and $30 \%$.

\subsection{Flexural Toughness Results Discussion}

A three point-loading test was performed and the results of load-deflection for rubberized mixtures with fine and coarse crumb rubber are presented in Table 4 and Table 5, respectively. Results of flexural toughness, determined by Equation 1, for all concrete mixtures are tabulated in Table 6. The results show that flexural toughness of concrete control mix, containing no rubber, was $11.71 \mathrm{kN} . \mathrm{mm}$ at the age of 28 days.

From the analysis, it has been found that at $10 \%$ 
replacement level of fine or coarse aggregate, the flexural toughness is $13.77 \mathrm{kN} . \mathrm{mm}$ and $16.31 \mathrm{kN} . \mathrm{mm}$ for fine and coarse rubberized mixes respectively. This indicates an increase in flexural toughness by $17.6 \%$ and $39.36 \%$ for $\mathrm{F}-10$ and $\mathrm{C}-10$ respectively when compared to control mix. At higher percent rubber replacement $(>10 \%)$, concrete flexural toughness does not follow a constant pattern.

Table 4. Average load and deflection results of mixtures with fine crumb rubber.

\begin{tabular}{|c|c|c|c|c|c|c|c|}
\hline \multicolumn{9}{|c|}{ Mix } \\
\hline \multicolumn{2}{|c|}{ Control } & \multicolumn{2}{|c|}{ F-10 } & \multicolumn{2}{c|}{ F-20 } & \multicolumn{2}{c|}{ F-30 } \\
\hline $\mathrm{P}(\mathrm{kgf})$ & $\Delta(\mathrm{mm})$ & $\mathrm{P}(\mathrm{kgf})$ & $\Delta(\mathrm{mm})$ & $\mathrm{P}(\mathrm{kgf})$ & $\Delta(\mathrm{mm})$ & $\mathrm{P}(\mathrm{kgf})$ & $\Delta(\mathrm{mm})$ \\
\hline 0.00 & 0.00 & 0.00 & 0.00 & 0.00 & 0.00 & 0.00 & 0.00 \\
\hline 78.33 & 0.31 & 87.33 & 0.51 & 68.00 & 0.63 & 60.00 & 0.66 \\
\hline 153.33 & 0.61 & 179.33 & 1.05 & 147.00 & 1.37 & 120.00 & 1.32 \\
\hline 248.33 & 0.78 & 257.67 & 1.29 & 217.00 & 1.89 & 171.67 & 1.58 \\
\hline 328.33 & 0.88 & 344.67 & 1.53 & 279.00 & 2.21 & 236.67 & 1.87 \\
\hline 400.00 & 0.98 & 431.00 & 1.71 & 371.50 & 2.42 & 298.33 & 2.13 \\
\hline 480.00 & 1.05 & 525.00 & 1.83 & 488.00 & 2.73 & 356.67 & 2.31 \\
\hline 573.33 & 1.08 & 606.67 & 1.95 & 605.50 & 3.05 & 416.67 & 2.46 \\
\hline 665.00 & 1.18 & 697.00 & 2.07 & 708.50 & 3.26 & 481.67 & 2.57 \\
\hline 731.67 & 1.18 & 784.67 & 2.25 & 829.02 & 3.47 & 570.00 & 2.71 \\
\hline 833.33 & 1.31 & 875.00 & 2.37 & 930.35 & 3.65 & 693.33 & 2.86 \\
\hline 1117.92 & 1.69 & 1106.00 & 2.68 & 1031.67 & 3.83 & 866.67 & 3.07 \\
\hline 1402.50 & 2.06 & 1337.00 & 2.99 & 1133.00 & 4.02 & 1040.00 & 3.27 \\
\hline
\end{tabular}

Table 5. Average load and deflection results of mixtures with coarse crumb rubber.

\begin{tabular}{|c|c|c|c|c|c|c|c|}
\hline \multicolumn{9}{|c|}{ Cix } \\
\hline \multicolumn{2}{|c|}{ Control } & \multicolumn{2}{c|}{ C-10 } & \multicolumn{2}{c|}{ C-20 } & \multicolumn{2}{c|}{ C-30 } \\
\hline $\mathrm{P}(\mathrm{kgf})$ & $\Delta(\mathrm{mm})$ & $\mathrm{P}(\mathrm{kgf})$ & $\Delta(\mathrm{mm})$ & $\mathrm{P}(\mathrm{kgf})$ & $\Delta(\mathrm{mm})$ & $\mathrm{P}(\mathrm{kgf})$ & $\Delta(\mathrm{mm})$ \\
\hline 0.00 & 0.00 & 0.00 & 0.00 & 0.00 & 0.00 & 0.00 & 0.00 \\
\hline 78.33 & 0.31 & 79.67 & 0.73 & 39.00 & 1.31 & 46.67 & 0.42 \\
\hline 153.33 & 0.61 & 159.67 & 1.46 & 78.67 & 2.64 & 101.67 & 0.92 \\
\hline 248.33 & 0.78 & 239.33 & 1.73 & 133.33 & 3.18 & 148.33 & 1.36 \\
\hline 328.33 & 0.88 & 324.67 & 1.93 & 205.00 & 3.44 & 201.67 & 1.82 \\
\hline 400.00 & 0.98 & 401.33 & 2.13 & 289.33 & 3.76 & 255.00 & 1.99 \\
\hline 480.00 & 1.05 & 478.33 & 2.33 & 377.67 & 4.03 & 311.67 & 2.09 \\
\hline 573.33 & 1.08 & 561.33 & 2.73 & 457.33 & 4.19 & 350.00 & 2.19 \\
\hline 665.00 & 1.18 & 643.00 & 2.93 & 557.00 & 4.35 & 420.00 & 2.29 \\
\hline 731.67 & 1.18 & 721.67 & 3.13 & 690.00 & 4.62 & 471.67 & 2.39 \\
\hline 833.33 & 1.31 & 796.00 & 3.26 & 797.00 & 4.78 & 570.00 & 2.56 \\
\hline 1117.92 & 1.69 & 995.00 & 3.62 & 965.00 & 5.03 & 805.00 & 2.96 \\
\hline 1402.50 & 2.06 & 1194.00 & 3.98 & 1133.00 & 5.28 & 1040.00 & 3.35 \\
\hline
\end{tabular}

Table 6. Flexural toughness results for all concrete mixtures \begin{tabular}{|c|c|c|c|c|c|c|c|}
\hline Mix & Control & F-10 & F-20 & F-30 & C-10 & C-20 & C-30 \\
\hline Energy absorbed (kN.mm) & 11.71 & 13.77 & 14.57 & 9.20 & 16.31 & 12.67 & 10.72 \\
\hline
\end{tabular}

For rubberized concrete mixes with $20 \%$ replacement by fine crumb rubber, concrete flexural toughness continued increasing to reach $14.57 \mathrm{kN}$.mm with $24.5 \%$ higher than control mix. Then, at 30\% replacement, concrete flexural toughness began to decrease till reaching a value of 9.20 $\mathrm{kN}$.mm which is dropped by $21.4 \%$ relative to concrete control mix. Moreover, for rubberized concrete mixes with coarse aggregate replacement, at $20 \%$ replacement level, flexural toughness diminished to $12.67 \mathrm{kN}$.mm with $8.2 \%$ higher than the control mix. While, at $30 \%$ replacement level, flexural toughness decreased to $10.72 \mathrm{kN} . \mathrm{mm}$ which dropped by $8.4 \%$ when compared to control mix. Figure 8 presents flexural toughness of tested concrete prisms against percent of incorporated crumb rubber.

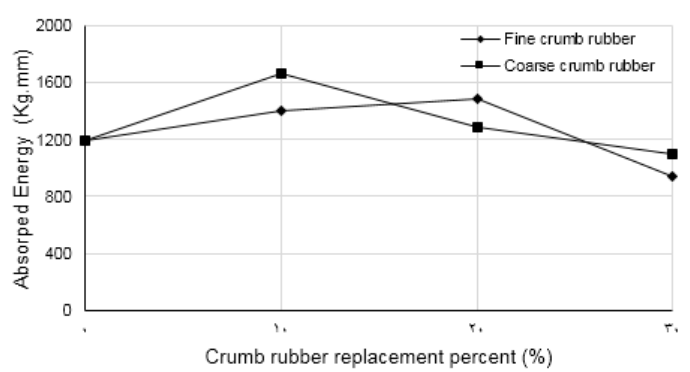

Figure 8. Flexural toughness versus percent replacement by fine and coarse crumb rubber.

\subsection{Impact Resistance Results Discussion}

The results obtained from impact resistance test at 28 days age of concrete specimens are the number of blows that cause first and failure cracking. Results are presented in Table 7. While, results of absorbed energy by impact, determined by Equation 2, are shown in Table 8. It's found that impact resistance of control concrete mix, with no rubber replacement, is $399.0 \mathrm{kN}$.mm for first cracking stage at which first crack is visible. While, the impact resistance is 478.8 $\mathrm{kN}$.mm for failure cracking stage at which concrete specimen is broken. Crack pattern of control mix at failure stage is shown in figure 9 .

Table 7. Initial and failure cracking blows obtained from impact test for all mixtures.

\begin{tabular}{|l|c|c|c|}
\hline Mix & Initial cracking blows $\left(\mathrm{N}_{1}\right)$ & Failure cracking blows $\left(\mathrm{N}_{2}\right)$ & $\mathrm{N}_{2}-\mathrm{N}_{1}$ \\
\hline Control & 20 & 24 & 4 \\
\hline F-10 & 22 & 30 & 8 \\
\hline F-20 & 28 & 41 & 13 \\
\hline F-30 & 43 & 60 & 17 \\
\hline C-10 & 26 & 41 & 15 \\
\hline C-20 & 62 & 90 & 28 \\
\hline C-30 & 75 & 111 & 36 \\
\hline
\end{tabular}

Table 8. Initial and failure energy absorbed after impact test.

\begin{tabular}{|l|c|c|}
\hline Mix & $\begin{array}{c}\text { Initial cracking energy } \\
(\mathrm{kN} . \mathrm{mm})\end{array}$ & $\begin{array}{c}\text { Failure cracking energy } \\
(\mathrm{kN} . \mathrm{mm})\end{array}$ \\
\hline Control & 399.0 & 478.8 \\
\hline F-10 & 438.9 & 598.5 \\
\hline F-20 & 558.6 & 818.0 \\
\hline F-30 & 857.9 & 1197.0 \\
\hline C-10 & 518.7 & 818.0 \\
\hline C-20 & 1236.9 & 1795.5 \\
\hline C-30 & 1496.3 & 2214.5 \\
\hline
\end{tabular}

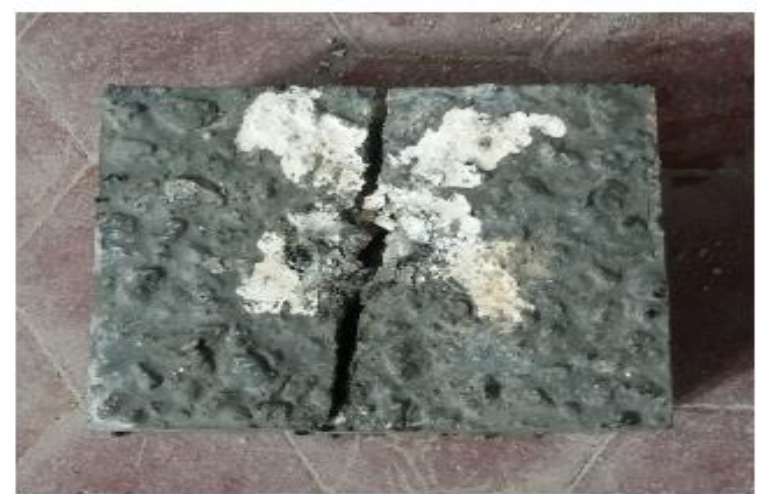

Figure 9. Control Specimen after impact test. 


\section{Abrasion Resistance, Flexural Toughness and Impact Resistance of Rubberized Concrete}

For rubberized concrete mixes, at 10\%, 20\% and 30\% replacement levels of fine aggregates by fine crumb rubber, concrete impact resistance for first cracking is improved and reached 438.9 kN.mm, 558.6 kN.mm and 857.9 kN.mm, respectively, with an increase of $10.0 \%, 40.0 \%$ and $115.1 \%$, respectively, when compared to concrete control mix. While, for other rubberized concrete mixes with incorporated coarse crumb rubber, the first cracking impact resistance increased to 518.7 kN.mm, 1236.9 kN.mm and $1496.3 \mathrm{kN} . \mathrm{mm}$, respectively. These values represent an increase by $30.0 \%$, $210.0 \%$ and $275.1 \%$, respectively, relative to control mix.

At failure cracking stage, considerable increase is noticed in the absorbed energy by rubberized concrete specimens. At the replacement levels by volume $10 \%, 20 \%$ and $30 \%$ of fine aggregates by fine crumb rubber, ultimate impact resistance increased to $598.5 \mathrm{kN} . \mathrm{mm}, 818.0 \mathrm{kN} . \mathrm{mm}$ and $1197.0 \mathrm{kN} . \mathrm{mm}$ which corresponds to an increase by $25.0 \%, 70.8 \%$ and $150.0 \%$, respectively, relative to control mix. Figure 10 shows cracking patterns of broken rubberized concrete specimens of mixtures containing fine crumb rubber, after impact test.

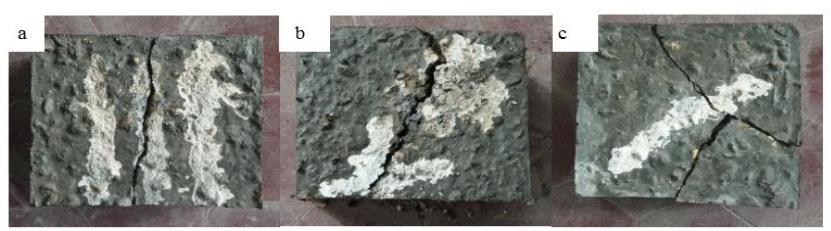

Figure 10. Impact test (a) F-10, (b) F-20, (c) F-30.

Other rubberized mixes containing coarse crumb rubber showed increased ultimate impact resistance of $818.0 \mathrm{kN} . \mathrm{mm}$, $1795.5 \mathrm{kN} . \mathrm{mm}$ and $2214.5 \mathrm{kN}$.mm, respectively at the same previous replacement percentages. Based on these results, ultimate cracking resistance of coarse crumb rubberized concrete mixes increased by $70.8 \%, 275.0 \%$ and $362.5 \%$, respectively, for $10 \%, 20 \%$ and $30 \%$ replacement levels. Cracking patterns of these mixtures are shown in figure 11. Once again, difference between blows that cause initial cracking and final cracking is increased with the increase of crumb rubber replacement level for both fine and coarse crumb rubberized concrete mixes. The difference is 8,13 and 17 blows for mixes with fine aggregate partially substituted by fine crumb rubber at previous replacement levels, while, it is 15, 28 and 36 blows for mixes with coarse aggregates partially substituted by coarse crumb rubber at the same replacement levels.

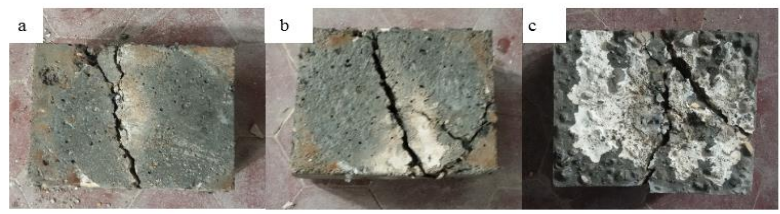

Figure 11. Impact test (a) C-10, (b) C-20, (c) C-30.

In figure 12, first and ultimate cracking energies of concrete mixtures are shown versus crumb rubber replacement percentage.

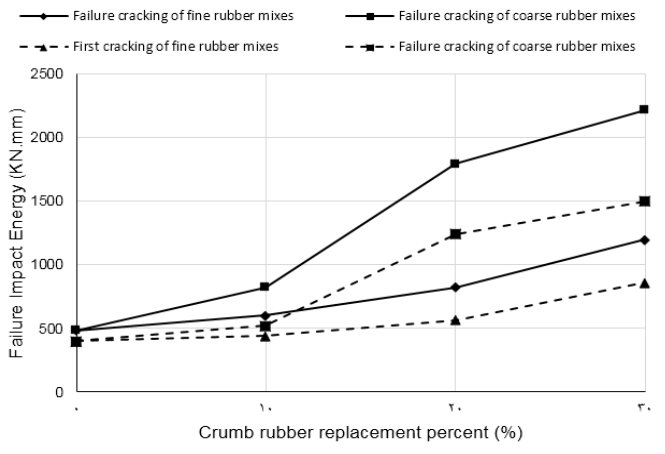

Figure 12. Initial and failure cracking impact energy versus percent replacement by fine and coarse crumb rubber.

\section{CONCLUSION}

In this research, abrasion resistance, flexural toughness and impact resistance of prepared concrete specimens were studied. Rubberized concrete mixtures were prepared with Crumb Rubber as a partial substituent to natural aggregates at levels $10 \%-30 \%$. The following conclusions are deduced from the previously obtained results presented in this paper:

- Compressive strength decreased as the rubber content increased. Concrete mixes with coarse aggregate replaced partially by coarse rubber show less compressive strength while comparing to mixes with fine rubber at the same replacement percent.

- Abrasion resistance increases as the rubber content increases. Concrete mixes containing fine crumb rubber gave higher abrasion resistance than mixes with coarse crumb rubber at the same replacement percent of aggregate by crumb rubber. Such improvement in abrasion resistance could be utilized in concrete highways, industrial floors, pavements, hydraulic structures and other surfaces subjected to abrasive forces due to moving objects on concrete surface during service life.

- Flexural toughness increases with the increase of rubber content up to $10 \%$ replacement by either fine or coarse rubber. For mixes with fine crumb rubber, flexural toughness increases and then decreases up to $30 \%$ replacement, while for mixes with coarse crumb rubber, flexural toughness decreases up to 30\% replacement.

- Initial and failure cracking impact resistance of concrete improves as content of incorporated crumb rubber increases. Concrete mixes containing coarse crumb rubber showed higher impact resistance and plastic energy when compared to mixes with fine crumb rubber at the same replacement percent of aggregates by crumb rubber. This improvement is due to the high ability of rubber materials in absorbing more energy developed by dropped weight.

\section{REFERENCES}

1. ACI Committee 544.2R-17 (2017). Report on the Measurement of Fresh State Properties and Fiber Dispersion of Fiber-Reinforced Concrete. ACI Committee 544.

2. ASTM C143M (2012). Standard Test Method for Slump of Hydraulic-Cement Concrete. ASTM International. 
3. ASTM C192M (2014). Standard Practice for Making and Curing Concrete Test Specimens in the Laboratory. ASTM International.

4. ASTM C494M (2013). Standard Specification for Chemical Admixtures for Concrete. ASTM International.

5. Azevedo, F., Pacheco-Torgal, F., Jesus, C., Aguiar, J. B. D., and Camões, A. (2012). "Properties and durability of HPC with tyre rubber wastes." Construction and Building Materials, 34, 186-191.

6. Benazzouk, A., Douzane, O., Mezreb, K., and Quéneudec, M. (2006). "Physico-mechanical properties of aerated cement composites containing shredded rubber waste." Cement and Concrete Composites, 28(7), 650-657.

7. Bravo, M., and Brito, J. D. (2012). "Concrete made with used tyre aggregate: durability-related performance." Journal of Cleaner Production, 25, 42-50.

8. BS 1338 (2003). Concrete paving blocks. Requirements and test methods. BSI.

9. BS EN 12390-3 (2002). Testing Hardened Concrete. Compressive Strength of Test Specimens. BSI, London, United Kingdom.

10. BS EN 197-1 (2011). Composition, specifications and conformity criteria for common cements. BSI.

11. Eiras, J., Segovia, F., Borrachero, M., Monzó, J., Bonilla, M., and Payá, J. (2014). "Physical and mechanical properties of foamed Portland cement composite containing crumb rubber from worn tires." Materials \& Design, 59, 550-557.

12. Eldin, N. N., and Senouci, A. B. (1994). "Measurement and prediction of the strength of rubberized concrete." Cement and Concrete Composites, 16(4), 287-298.

13. Gerges, N. N., Issa, C. A., and Fawaz, S. A. (2018). "Rubber concrete: Mechanical and dynamical properties." Case Studies in Construction Materials, 9

14. Gesoğlu, M., and Güneyisi, E. (2011). "Permeability properties of self-compacting rubberized concretes." Construction and Building Materials, 25(8), 3319-3326.

15. Gesoğlu, M., Güneyisi, E., Khoshnaw, G., and Ipek, S. (2014) "Abrasion and freezing-thawing resistance of pervious concretes containing waste rubbers." Construction and Building Materials, 73, 19-24.

16. Gupta, T., Sharma, R. K., and Chaudhary, S. (2015). "Impact resistance of concrete containing waste rubber fiber and silica fume." International Journal of Impact Engineering, 83, 76-87.

17. Ismail, M. K., and Hassan, A. A. (2017). "An experimental study on flexural behaviour of large-scale concrete beams incorporating crumb rubber and steel fibres." Engineering Structures, 145, 97-108.

18. Kovler, K., and Roussel, N. (2011). "Properties of fresh and hardened concrete." Cement and Concrete Research, 41(7), 775-792.

19. Martínez-López, M., Martínez-Barrera, G., Coz-Díaz, J. J. D. Martínez-Martínez, J. E., Gencel, O., Ribeiro, M. C., and Varela-Guerrero, V. (2018). "Polymer waste materials as fillers in polymer mortars: experimental and finite elements simulation." Case Studies in Construction Materials, 9.

20. Mohammed, B. S., Adamu, M., and Liew, M. S. (2018). "Evaluating the effect of crumb rubber and nano silica on the properties of high volume fly ash roller compacted concrete pavement using non-destructive techniques." Case Studies in Construction Materials, 8, 380-391.

21. Mohammed, B. S., Hossain, K. M. A., Swee, J. T. E., Wong, G., and Abdullahi, M. (2012). "Properties of crumb rubber hollow concrete block." Journal of Cleaner Production, 23(1), 57-67.

22. Mohammed, B. S., Liew, M. S., Alaloul, W. S., Al-Fakih, A., Ibrahim, W., and Adamu, M. (2018). "Development of rubberized geopolymer interlocking bricks." Case Studies in Construction Materials, 8, 401-408.

23. Najim, K. B., and Hall, M. R. (2012). "Mechanical and dynamic properties of self-compacting crumb rubber modified concrete." Construction and Building Materials, 27(1), 521-530.

24. Oikonomou, N., and Mavridou, S. (2009). "Improvement of chloride ion penetration resistance in cement mortars modified with rubber from worn automobile tires." Cement and Concrete Composites, 31(6), 403-407.

25. Pacheco-Torgal, F., Ding, Y., and Jalali, S. (2012). "Properties and durability of concrete containing polymeric wastes (tyre rubber and polyethylene terephthalate bottles): An overview." Construction and Building Materials, 30, 714-724.

26. Raghavan, D., Huynh, H., and Raghavan, D. (1998). "Workability, mechanical properties, and chemical stability of a recycled tyre rubber-filled cementitious composite." Journal of Materials Science, 33(7), 1745-1752.

27. Segre, N., and Joekes, I. (2000). "Use of tire rubber particles as addition to cement paste." Cement and Concrete Research, 30(9), 1421-1425.
28. Shen, W., Shan, L., Zhang, T., Ma, H., Cai, Z., and Shi, H. (2013). "Investigation on polymer-rubber aggregate modified porous concrete." Construction and Building Materials, 38, 667-674.

29. Shu, X., and Huang, B. (2014). "Recycling of waste tire rubber in asphalt and portland cement concrete: An overview." Construction and Building Materials, 67, 217-224.

30. Siddique, R., and Naik, T. R. (2004). "Properties of concrete containing scrap-tire rubber - an overview." Waste Management, 24(6), 563-569.

31. Thomas, B. S., Damare, A., and Gupta, R. (2013). "Strength and durability characteristics of copper tailing concrete." Construction and Building Materials, 48, 894-900.

32. Uygunoğlu, T., and Topçu, I. B. (2010). "The role of scrap rubber particles on the drying shrinkage and mechanical properties of self-consolidating mortars." Construction and Building Materials, 24(7), $1141-1150$

\section{AUTHORS PROFILE}

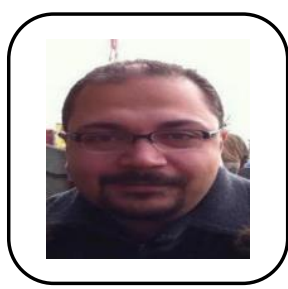

Hatem H. Ibrahim- he is an assistant professor in department of structural at faculty of engineering Cairo university. He has master's in science from Cairo university and $\mathrm{PhD}$ degree from university of Calgary, Alberta, Canada. His area of research is precast concrete and properties and strength of materials.

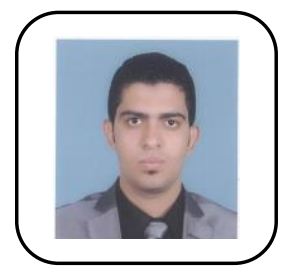

Ahmed Z. Saber, Graduate Master Student, Structural Engineering Department, Faculty of Engineering, Cairo University, Giza, Egypt. He completed his MSc degree from Cairo University and is working as structural engineer at Enppi, Egypt.

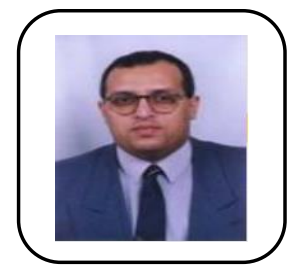

Hossma A. Hodhod - he is a professor in department structural at faculty of engineering Cairo university.He has master's in science from Cairo university and $\mathrm{PhD}$ degree from university of Tokyo. He has published many papers in the field of properties and strength of materials. 